\title{
Occupational Segregation in a Country of Recent Mass Immigration: Evidence from Spain
}

\author{
Olga Alonso-Villar ${ }^{\#}$ and Coral del Río
}

Universidade de Vigo

\begin{abstract}
The aim of this paper is to study the occupational segregation of immigrants in Spain. It analyzes whether age, educational level, gender, region of origin, and years of residence in Spain affect the distribution of immigrants across occupations. In addition, given the remarkable increase of immigrants in the last few years and the adjustments that have occurred in the Spanish labor market from the current economic crisis, the recent evolution of the occupational segregation of immigrants is addressed as well. For these purposes, several measures recently proposed in the literature are used.
\end{abstract}

Keywords: Immigration; Occupational segregation; Local segregation

JEL Classification: D63; J15; J16; J71

\footnotetext{
\# Correspondence address: Universidade de Vigo; Facultade de CC. Económicas; Departamento de Economía Aplicada; Campus Lagoas-Marcosende s/n; 36310 Vigo; Spain. Tel.: +34 986812507; fax: +34 986812401; e-mail: ovillar@uvigo.es
} 


\section{Introduction}

In the last decade, Spain has experienced a remarkable increase in its immigrant population — the immigration rate rose from $1.4 \%$ in 1996 to $12.1 \%$ in $2009^{1}$ —which has stimulated a debate in academia about the consequences of this phenomenon. The literature has dealt, on the one hand, with the effects of immigration on native employment, the wage gap between immigrant and native workers, and the assimilation of immigrants in the labor market (Carrasco et al., 2004; Amuedo-Dorantes and De la Rica, 2007; Bentolilla et al., 2007; Canal-Domínguez and Rodríguez-Gutiérrez, 2008; Izquierdo et al., 2009). ${ }^{2}$ On the other hand, the effects of immigration on the welfare state have been addressed as well (Collado et al., 2004; Vázquez et al., 2008; Muñoz de Bustillo and Antón, 2009). Yet, research on the quantification of the occupational segregation of immigrant workers in the Spanish labor market barely exists, ${ }^{3}$ despite the important contribution of segregation between native and foreign-born workers in explaining their wage gap (Simón et al., 2008). Evidence for other countries is also scarce since the literature on occupational segregation has mainly focused on segregation by gender, whereas nationality/race has received less attention, especially in Europe. ${ }^{4}$

There are several reasons, however, for discrepancies between the numbers of immigrant and native workers across occupations. First, the job opportunities for newly arrived immigrants are likely to depend on migrant networks, which may fuel their concentration in some types of occupations. Second, language and cultural differences between the sending and the receiving country may hinder the process of immigrant assimilation, especially if the employers in the latter country possess discriminatory attitudes. Third, the educational achievement of immigrants may depart from that of the natives, not only

\footnotetext{
${ }^{1}$ See the revised version of the municipal census undertaken by the Spanish Institute of Statistics (INE, 2009, 2010a).

${ }^{2}$ In addition, the spatial migration patterns of immigrants within the national territory have been addressed. For a recent work, see Rehet and Silvestre (2009).

${ }^{3}$ Caparrós and Navarro (2008) measure the discrepancy between immigrant and native workers when considering nine broad occupations and two types of contracts (temporary versus permanent). In order to analyze the effects of immigration on native employment patterns, Amuedo-Dorantes and De la Rica (2008) also study the occupational distribution of immigrants across nine occupations. However, none of these papers quantifies the segregation of subgroups of immigrants.

${ }^{4}$ For studies in the U.S. and Australian labor markets, see Albelda (1986), King (1992), Springs and Williams (1996), Parasnis (2006), and Queneau (2009).
} 
regarding the number of schooling years, but also regarding the specific knowledge required in the host country, as in the case of lawyers.

To fill some of that gap, this paper aims to analyze occupational segregation in the Spanish labor market by immigrant status. In particular, it examines whether age, educational level, gender, region of origin, and years of residence in Spain affect the distribution of immigrants across occupations. In addition, given the remarkable increase in immigrants in the last few years and the adjustments occurring in the Spanish labor market because of the current economic crisis, the recent evolution of the occupational segregation of immigrants is addressed as well. For these purposes, the tools proposed by Alonso-Villar and Del Río (2010) and Del Río and Alonso-Villar (2010a) are used. ${ }^{5}$

It is important to keep in mind that most segregation indexes existing in the literature measure overall segregation rather than the segregation of a particular demographic group, since they quantify the discrepancies among the distributions of all population subgroups across organizational units. Thus, the popular index of dissimilarity proposed by Duncan and Duncan (1955), the modified version put forward by Karmel and MacLachlan (1988), the Gini index offered by Silber (1989), and the square root proposed by Hutchens (2001) measure the divergence between the distributions of two demographic groups across units-for example, the distributions of female and male workers across occupations, in the case of occupational segregation by gender. In recent years, several indexes have been proposed as well to quantify overall segregation in a multigroup context (Silber, 1992; Reardon and Firebaugh, 2002; Frankel and Volij, 2007).

Nevertheless, it is interesting not only to measure aggregate segregation, but also to explore the segregation of target groups (for example, total immigrant workers or immigrant workers by country of origin). This issue was initially tackled by Moir and Selby Smith (1979) in the binary case. However, so far as we know, only Alonso-Villar and Del Río (2010) and Del Río and Alonso-Villar (2010a) have dealt with this matter, labeled local segregation, within an axiomatic framework in a context of multiple groups. In their study, the distribution of the target demographic group across units is compared

\footnotetext{
${ }^{5}$ Del Río and Alonso-Villar (2010b) use the same tools to compare the segregation of immigrant women with that of native women and immigrant men, even though the evolution of segregation and the effects of age, educational level, and years of residence were not considered in their analysis.
} 
with that of the total population. The target group is segregated so long as its distribution across occupations departs from the employment structure of the economy.

This approach does not imply, however, that the segregation of a demographic group can be quantified independently of the rest of groups. Local segregation is indeed a phenomenon that requires considering the relative position of individuals with respect to others - as happens when measuring overall segregation — so that if the distribution of a demographic group across organizational units varies, this change may affect not only the segregation level of this group, but also that of other groups since the distribution of reference (that of the whole population) may have been modified. These local segregation measures, which satisfy several basic properties, are naturally related to the corresponding overall measures existing in the literature, since when they are aggregated according to the demographic weights of the mutually exclusive subgroups into which the population can be partitioned, they add up to the whole segregation.

We use these local measures to study segregation by immigrant status in Spain, which is interesting in an international context because it is representative of those countries that, despite not having a long tradition as receiving countries, have witnessed their immigration rates increasing very rapidly in the last few years. The results obtained in this study will be especially interesting if future research compares them with those of other countries having different timing immigration patterns. Our approach departs from that of previous literature mainly for two reasons. On the one hand, we explicitly quantify the segregation of immigrant workers rather than the aggregate segregation of both immigrants and natives as usually done. On the other hand, as far as we know, this is the first time that the segregation of subgroups of immigrants by age, educational achievements, and years of residence has been measured, which has been possible due to the new measures (indexes and curves) recently proposed in the literature (Alonso-Villar and Del Río, 2010; Del Río and Alonso-Villar, 2010a).

The paper is structured as follows. Section 2 presents the segregation measures that will be applied. Section 3 offers a detailed analysis of the occupational segregation of immigrants in Spain before the current economic crisis, focusing on 2007, while Section 4 shows its evolution from 1996 to 2009. Finally, Section 5 concludes. 


\section{Measuring the segregation of a target group}

As mentioned above, when segregation is measured, the indexes commonly used quantify overall segregation since they measure whether the population subgroups into which the economy can be partitioned (men/women, blacks/whites/Asians/Hispanics, etc.) are evenly distributed across organizational units (Duncan and Duncan, 1955; Silber, 1992; Hutchens, 2001, 2004, Frankel and Volij, 2007; inter alia). However, it is interesting not only to measure aggregate segregation, but also to explore the segregation of a target group. Alonso-Villar and Del Río (2010) (henceforth AV-DR) tackle this matter in a multigroup context by proposing an axiomatic framework in which to study the occupational segregation of any population subgroup. In doing so, they propose some basic axioms for local segregation measures (i.e., for measuring the segregation of any target group) and offer several measures satisfying them. We introduce these tools here.

Consider that there are $T$ workers in the economy allocated among $J>1$ occupations according to distribution $t \equiv\left(t_{1}, t_{2}, \ldots, t_{J}\right)$, where $T=\sum_{j} t_{j}$. Vector $t$ represents the distribution of reference against which that of any population subgroup is compared. Let us denote by $c^{g} \equiv\left(c_{1}^{g}, c_{2}^{g}, \ldots, c_{J}^{g}\right)$ the distribution of the target group $g$ in which we are interested, $(g=1, \ldots, G)$, where $c_{j}^{g} \leq t_{j}$. Distribution $c^{g}$ could represent, for example, immigrant workers, those for a given country, or any other group of citizens in which we are interested. Therefore, the total number of workers in occupation $j$ is $t_{j}=\sum_{g} c_{j}^{g}$, and the total number of individuals of target group $g$ is $C^{g}=\sum_{j} c_{j}^{g}$.

In order to compare the segregation level of two distributions, these authors propose, first, the use of local segregation curves, which are related to the Lorenz curves used in the literature of income distribution. The local segregation curve for target group $g, S^{g}$, can built as follows. First, the occupations have to be ranked in ascending order of the ratio $\frac{c_{j}^{g}}{t_{j}}$, and second, the cumulative proportion of employment, $\sum_{i \leq j} \frac{t_{i}}{T}$, is plotted on the horizontal axis; and the cumulative proportion of individuals of the target group 
(immigrants from Latin America, for example), $\sum_{i \leq j} \frac{c_{i}^{g}}{C^{g}}$, is plotted on the vertical axis. ${ }^{6}$ Therefore, each point of the local segregation curve of Latin American immigrants indicates the proportion of these workers corresponding to each cumulative decile of total employment. The first decile distribution represents $10 \%$ of total employment, and it includes those occupations in which Latin American workers have the lowest relative presence; the second cumulative decile represents $20 \%$ of total employment, and it also includes those occupations in which the target group has the lowest relative presence; and so on. Therefore, the local segregation curve shows the under-representation of the target group with respect to the employment structure of the economy, decile by decile. In the case where the target group was distributed among occupations in the same manner as the distribution of total employment, the local segregation curve would be equal to the $45^{\circ}$ line, and no segregation would exist for that demographic group. The further away the curve is from this line, the higher the occupational segregation of the target group.

AV-DR show that when the segregation curve of a distribution is above that of another (which can represent either that of another demographic group or that of the same target group in another period of time), any local segregation index satisfying some basic properties will conclude that segregation is higher for the lower distribution. This makes the use of these curves a powerful procedure for empirical analysis since it allows identifying those cases in which the conclusions reached are robust against changes in the local segregation index used. However, if the curves cross, or if one is interested in quantifying the extent of segregation, these authors propose to use several local indexes which satisfy some basic properties:

$$
G^{g} \equiv G\left(c^{g} ; t\right)=\frac{\sum_{i, j} \frac{t_{i}}{T} \frac{t_{j}}{T}\left|\frac{c_{i}^{g}}{t_{i}}-\frac{c_{j}^{g}}{t_{j}}\right|}{2 \frac{C^{g}}{T}},
$$

\footnotetext{
${ }^{6}$ In a binary context, the overall segregation curve proposed by Duncan and Duncan (1955) is obtained instead by comparing the distribution of one population subgroup among organizational units with that of the other subgroup (women against men, for example).
} 


$$
\begin{gathered}
\Phi_{a}^{g} \equiv \Phi_{a}\left(c^{g} ; t\right)=\left\{\begin{array}{l}
\frac{1}{a(a-1)} \sum_{j} \frac{t_{j}}{T}\left[\left(\frac{c_{j}^{g} / C^{g}}{t_{j} / T}\right)^{a}-1\right] \text { if } a \neq 0,1, \\
\sum_{j} \frac{c_{j}^{g}}{C^{g}} \ln \left(\frac{c_{j}^{g} / C^{g}}{t_{j} / T}\right) \text { if } a=1
\end{array}\right. \\
D^{g} \equiv D\left(c^{g} ; t\right)=\frac{1}{2} \sum_{j}\left|\frac{c_{j}^{g}}{C^{g}}-\frac{t_{j}}{T}\right| .
\end{gathered}
$$

The first measure is a variation of the classic Gini index, the second represents a family of indexes related to the generalized entropy family ( $a$ can be interpreted as a segregation aversion parameter), and the third is a variation of the index of dissimilarity. ${ }^{7}$ Both $D^{g}$ and $G^{g}$ take values within the interval $[0,1)$, while $\Phi_{a}^{g}$ is not bounded. These indexes quantify the "distance" between curve $S^{g}$ and the $45^{\circ}$ line, i.e., they measure to what extent the distribution of the target group across occupations departs from the employment structure of the economy. However, each index gives a different weight to these discrepancies since, even though all of them have some basic properties in common, they disagree regarding additional properties (see AV-DR). ${ }^{8}$ In any case, one should keep in mind that when curves do not cross, the conclusion reached with index $G^{g}$ and any of the members of the family of indexes $\Phi_{a}^{g}$ is consistent with the criterion given by the curves.

\section{Segregation of Immigrant Workers in Spain}

In an international context, Spain has seen an extraordinary rise in the number of immigrants in just a few years (Figure 1). This increase means that Spain’s immigration rate has reached a value similar to that of countries with much longer migrant traditions, like France, Germany, the United Kingdom, and the United States (see Figure 2).

Given the remarkable presence of immigrants in the current Spanish labor market, it seems timely to analyze their distribution across occupations. For this purpose, we use the Labor Force Survey (EPA) conducted by the Spanish Institute of Statistics (INE) by following Eurostat's guidelines. This survey offers labor market information for a representative sample of Spanish households and is commonly used for international comparisons. Our

\footnotetext{
${ }^{7}$ The latter index was proposed by Moir and Selby Smith (1979) even though its properties are studied in AV-DR.

${ }^{8}$ These differences also appear in the literature of income distribution when measuring inequality and poverty with indexes consistent with the Lorenz and TIP criteria, respectively.
} 
data set corresponds to the second quarter of each year from 1996 through 2009. Occupations are considered at a two-digit level of the CNO-1994 (National Classification of Occupations), and the list includes 66 occupations.

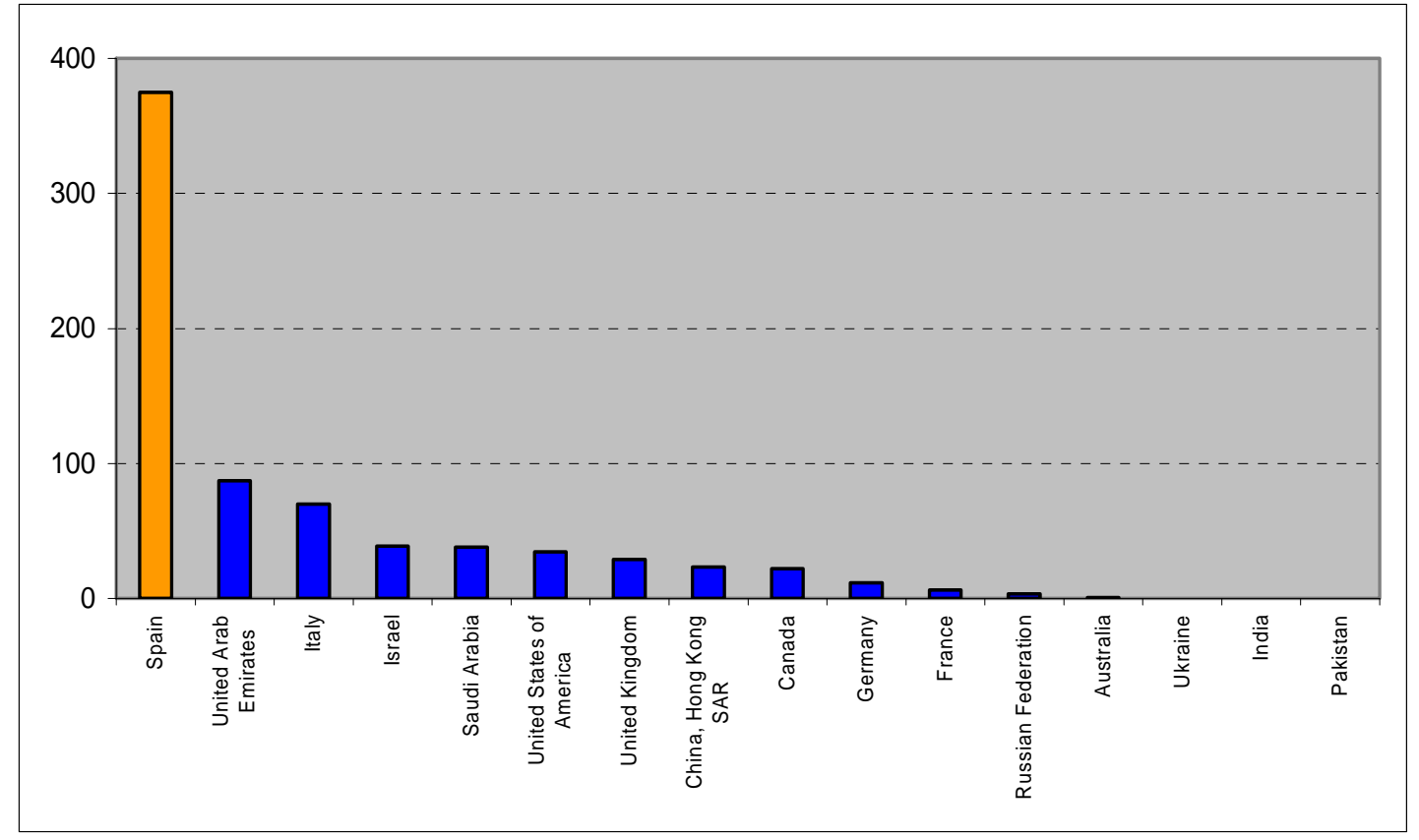

Figure 1: Migration growth between 1995 and 2005 for the countries with the highest migrant stocks in 2005. Source: United Nations, 2009.

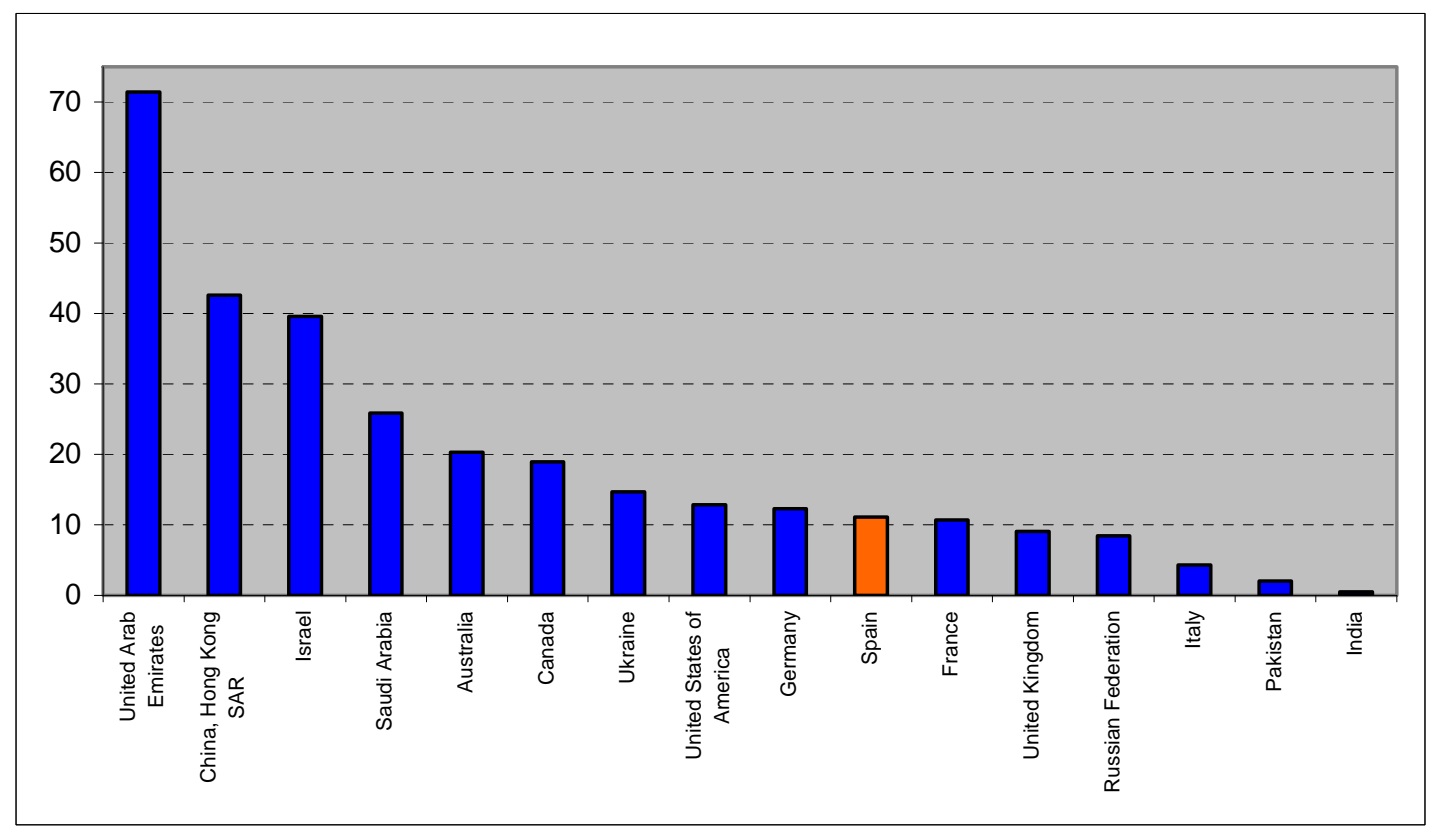

Figure 2: Migrant stock versus population in 2005 (\%) for the countries with the highest migrant stocks. Source: United Nations, 2009. 
We start the analysis by exploring the occupational segregation level of several subgroups of immigrants, classified by educational level, age, gender, years of residence in Spain, and region of origin. For this purpose, we choose the second quarter of 2007 since we are interested in quantifying segregation in a year of high employment and immigration rates (see Figures 3 and 4). In the next section, we deal with the evolution of occupational segregation of immigrant workers during the whole period. ${ }^{9}$

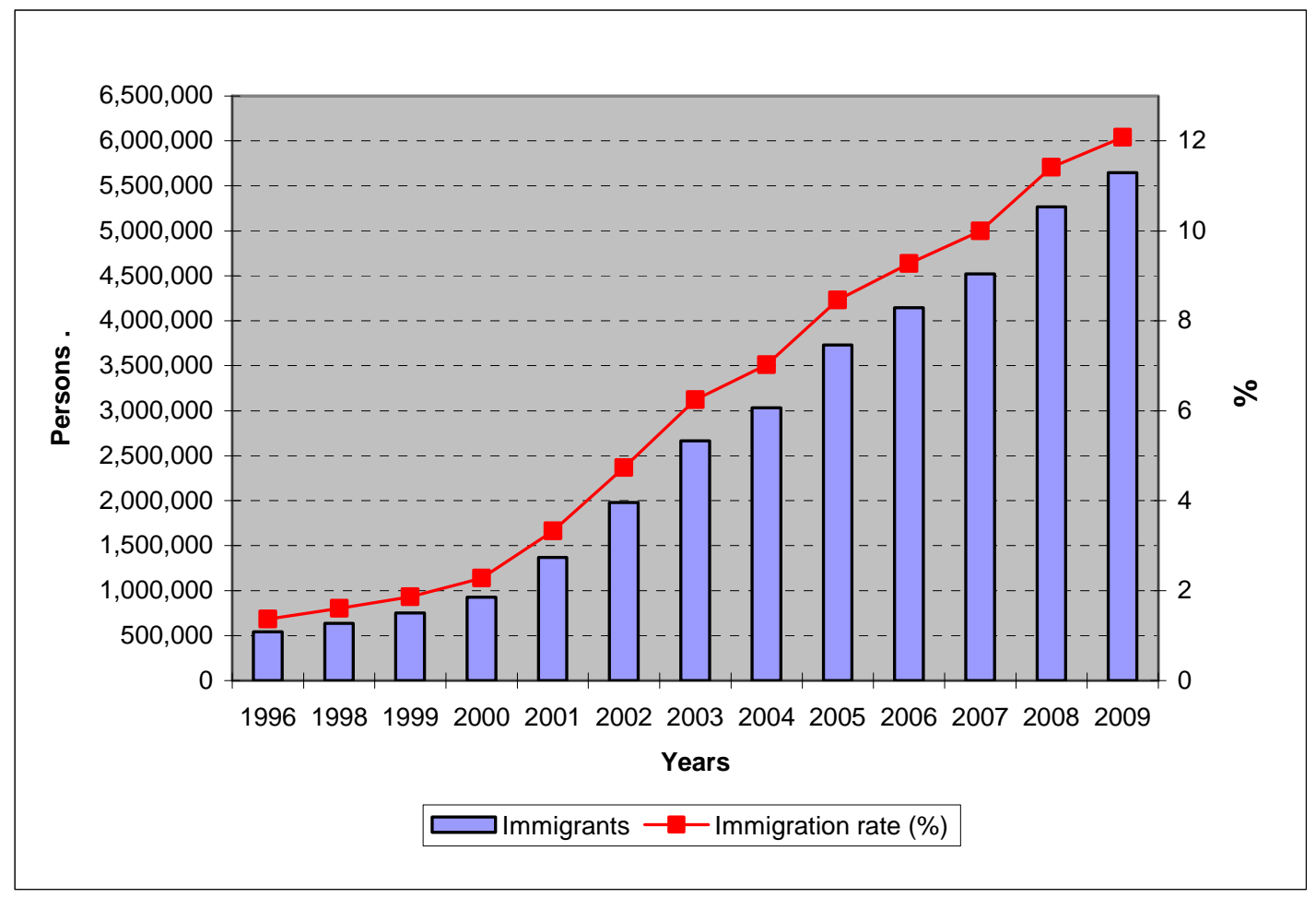

Figure 3. Number of immigrants and immigration rates (1996-2009). Source: Municipal Census, INE (2009, 2010a).

A summary of the main characteristics of the immigrant workers in 2007, who represent 16.3 of the employed population, is given in the Appendix (Table 6). Three educational groups of workers have been considered: low-educated (those who have not finished secondary school); intermediate-educated (those who have completed secondary school);

\footnotetext{
${ }^{9}$ In the second quarter of 2007, this survey gathered information on 70,506 employed individuals, 6,210 of whom were immigrants. By immigrant population, we mean those persons born outside of Spain and also to those born in Spain who possess a foreign or double nationality. The reason for this is that the performance of this group could be different from that of individuals born in Spain who have only Spanish nationality so long as the former can be perceived by employers as non-Spanish citizens. In any case, this group represents only 0.87 percent of immigrant workers in 2007; therefore, its inclusion in the immigrant group should not have a great effect on the results.
} 
and highly-educated (those who have a college degree). ${ }^{10}$ Immigrant workers have a higher educational level than native workers (59\% compared to 55.8\% have finished, at least, secondary school), even though the proportion of immigrants with university degrees is over 10 percentage points lower. ${ }^{11}$ Immigrant workers are also younger and the presence of women among them is higher relative to natives (43.6\% versus $40.5 \%$ ). In addition, $18.5 \%$ of immigrant workers have been in Spain for less than 3 years, while $23.4 \%$ have 10 or more years of residence in the country. ${ }^{12}$

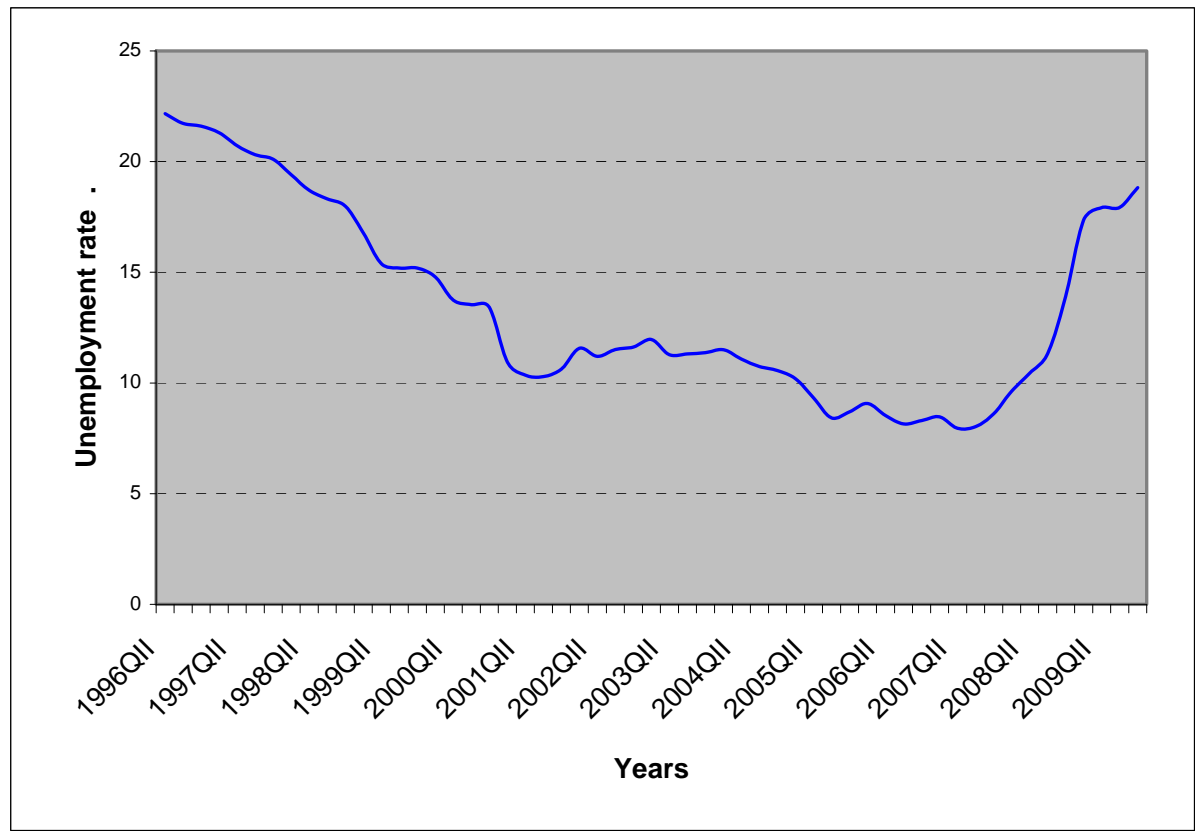

Figure 4. Evolution of the unemployment rate (1996-2009). Source: INE (2010b).

\subsection{Segregation of immigrants by educational level}

First, workers are classified into the three educational groups mentioned above. Figure 5 shows the corresponding segregation curves for immigrants (I) and natives $(\mathrm{N})$, which are shown in two different graphs for the sake of clarity. We want to call attention to the fact that highly-educated immigrants have a clearly lower segregation than the remaining subgroups of immigrants since their curve is above that of the others. Consequently, any

\footnotetext{
${ }^{10}$ It also includes those who have obtained a degree in "Formación Profesional Superior” (vocational training, $2^{\text {nd }}$ technical college).

${ }^{11}$ The proportion of immigrants with a university degree is particularly high among workers from the EU and other developed countries, clearly surpassing that of natives.

${ }^{12}$ Newly arrived workers are mainly from European countries outside the EU bloc and Latin America, while two out of three immigrants from the EU bloc and other developed countries have been in Spain for 10 or more years.
} 
of the local indexes consistent with these curves would necessarily lead to a lower segregation level for highly-educated immigrants than for the remaining groups. Yet, given that the other two curves do cross in the first percentiles of the employment distribution, the use of local indexes seems the most appropriate course to take in these cases. Table 1 offers six of the local indexes defined in Section 2: those corresponding to the generalized entropy family $\Phi_{a}^{g}(a=0.1,0.5,1$, and 2$)$, the (local) Gini index $\left(G^{g}\right)$, and the (local) index of dissimilarity $\left(D^{g}\right)$. These indexes show that immigrants with an intermediate educational level are distinctly less segregated than those with low education.
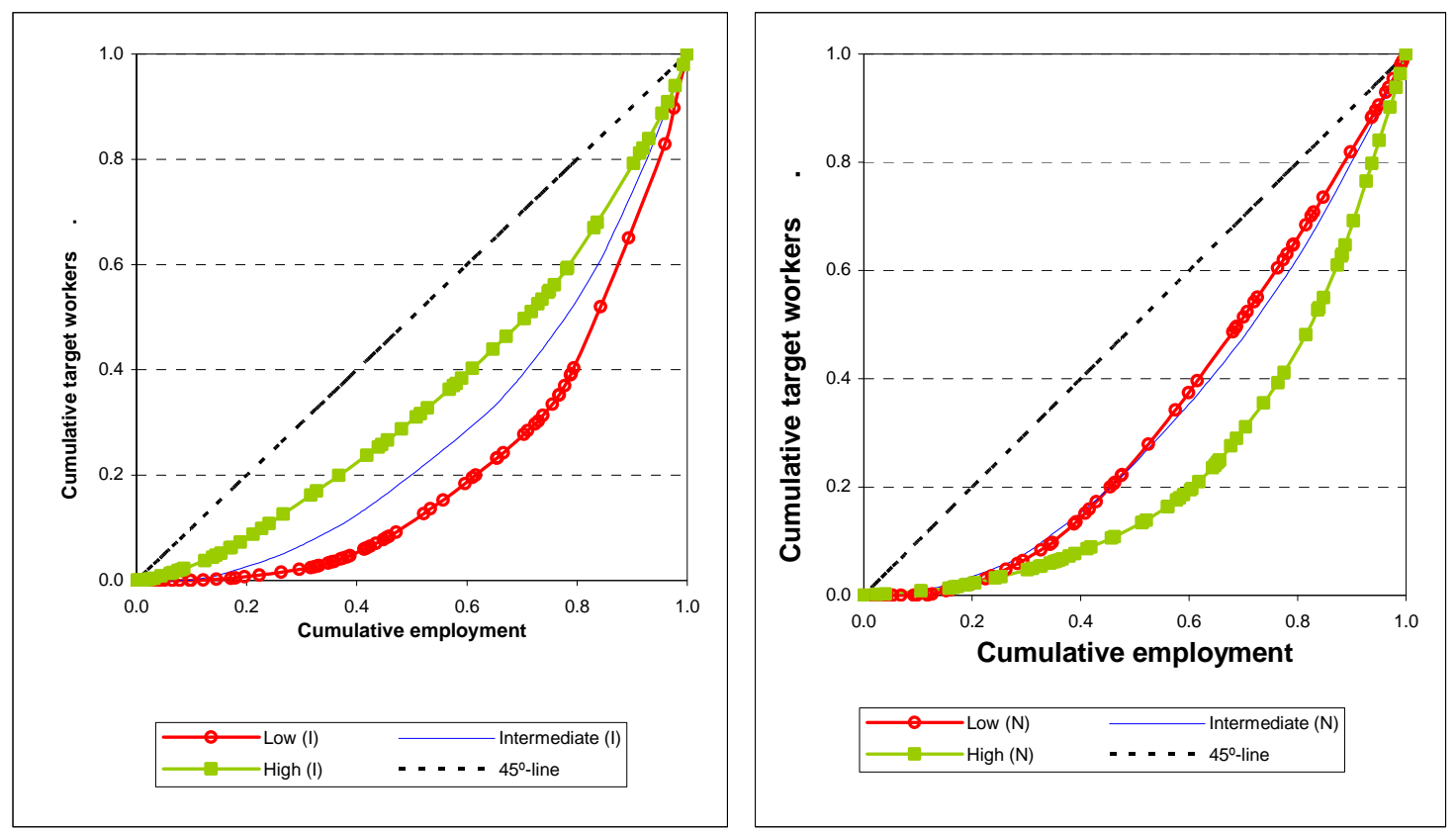

Figure 5. Segregation curves for immigrants and natives by educational level (2007).

However, it is important to note that education achievements do not affect immigrants and natives in the same way. Thus, as shown in Figure 5, the segregation curve for native workers with a high education is below those of other natives for most percentiles (the indexes are given in the Appendix, Table 7), which suggests that highly-educated natives tend to be concentrated in certain types of occupations. The fact that immigrants with a high education level are more evenly distributed across occupations than are similar natives suggests that immigrants may be working in jobs that do not necessarily match their skills (which is consistent with the higher probability of over-education in the group of immigrants found by Fernández and Ortega, 2008). In fact, when examining the distribution of each subgroup of immigrants across quintiles of total jobs (ranked from low 
to high immigrant presence $)^{13}$ we find that immigrants with a low level of education tend to concentrate in occupations with a strong immigrant presence (see Figure 6, bar 1, quintile 5), while those with a high educational level work in occupations with both high and low immigrant presence (Figure 6, bar 3, quintiles 1 and 5). ${ }^{14}$

\begin{tabular}{|c|c|c|c|c|c|c|}
\hline LOCAL SEGREGATION & $\Phi_{0.1}^{g}$ & $\Phi_{0.5}^{g}$ & $\Phi_{1}^{g}$ & $\Phi_{2}^{g}$ & $D^{g}$ & $G^{g}$ \\
\hline Low education & 1.50 & 0.66 & 0.55 & 0.60 & 0.43 & 0.56 \\
\hline Intermediate education & 1.07 & 0.41 & 0.32 & 0.31 & 0.32 & 0.43 \\
\hline High education & 0.21 & 0.15 & 0.14 & 0.15 & 0.21 & 0.29 \\
\hline
\end{tabular}

Table 1. Local segregation indexes for immigrants by educational level (2007)

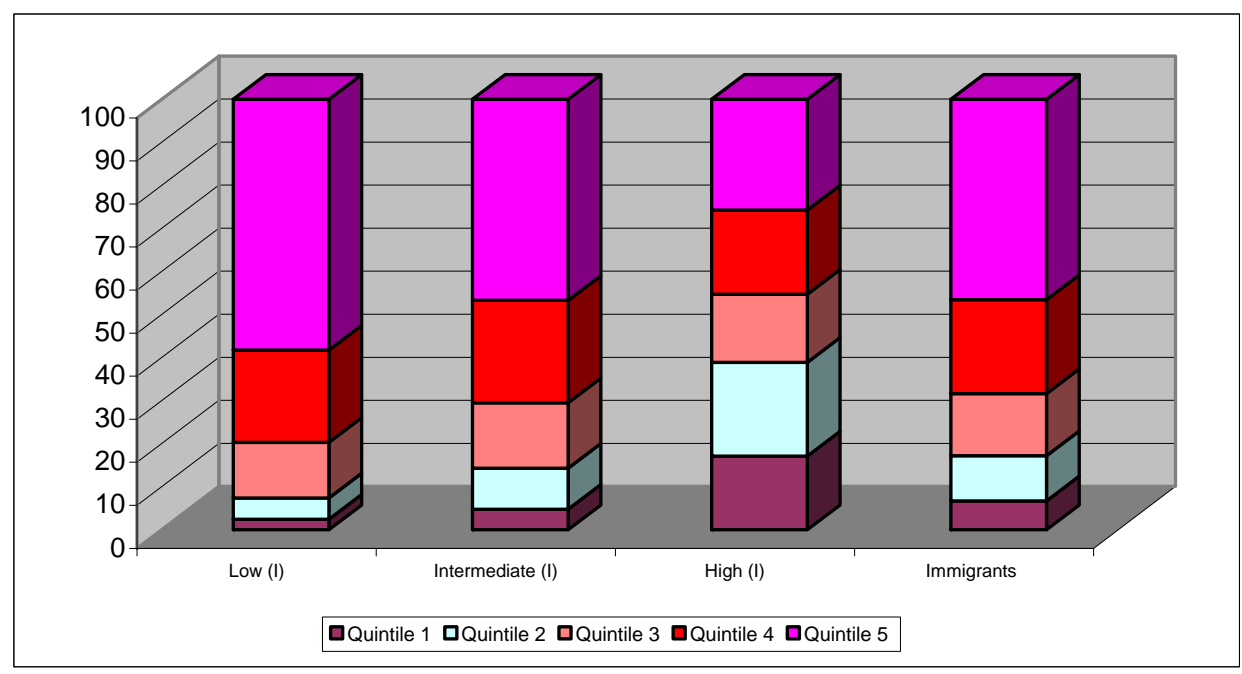

Figure 6. Distributions of immigrants across quintiles by educational level (2007).

\subsection{Segregation of immigrants by gender}

Del Río and Alonso-Villar (2010b) show that immigrant women in Spain suffer a double segregation in the labor market since, when analyzing their distribution across occupations, the authors find them to be much more segregated than both native women and immigrant men. Regarding immigrant men, the authors also find that they are clearly

\footnotetext{
${ }^{13}$ The first quintile, which represents $20 \%$ of total employment, includes those occupations where immigrants have the lowest share, while the fifth quintile includes those with the highest. The top (bottom) 10 occupations with the highest (lowest) immigrant presence are given in the Appendix (Table 8). For a detailed analysis of these tools, see Del Río and Alonso-Villar (2010a).

${ }^{14}$ The corresponding figure for native workers is given in the Appendix (Figure 15)--occupations are ranked from low to high native presence. The figure of natives suggests a pattern rather different from that of immigrants since in the former case those workers with intermediate and low levels of education are more evenly distributed than those with a high level.
} 
more segregated than native men, while the comparison between immigrant men and native women leads to a different conclusion depending on the index used (even though segregation tends to be higher for immigrant men according to most indexes).

Here we go a step further by calculating the contribution of female and male immigrants to the occupational segregation of immigrants. For this purpose, we use the decomposition of index $\Phi_{2}^{g}$ (see Del Río and Alonso-Villar, 2010a). In order to obtain the contribution of women to the segregation of the whole group of immigrants, first, we have to calculate the

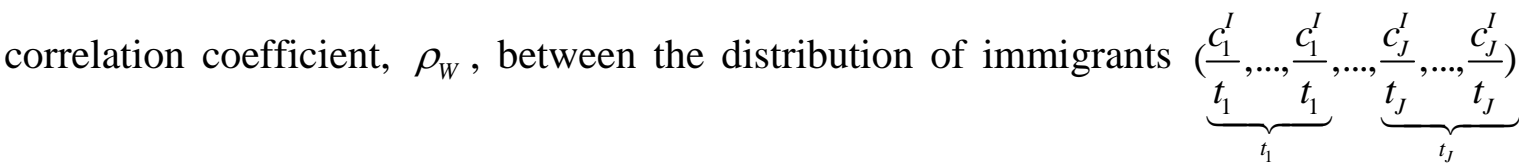
and the distribution of immigrant women $(\underbrace{\frac{c_{1}^{W}}{t_{1}}, \ldots, \frac{c_{1}^{W}}{t_{1}}}_{t_{1}}, \ldots, \underbrace{\frac{c_{J}^{W}}{t_{J}}, \ldots, \frac{c_{J}^{W}}{t_{J}}}_{t_{J}})$, where the proportion of immigrants in each occupation $j, \frac{c_{j}^{I}}{t_{j}}$, and the proportion of immigrant women in each occupation $j, \frac{c_{j}^{W}}{t_{j}}$, appear $t_{j}$ times. Second, the local segregation level of immigrants given $\Phi_{2}\left(c^{I} ; t\right)$ and that of immigrant women, $\Phi_{2}\left(c^{W} ; t\right)$, have to be calculated. Finally, the contribution of female immigrants to the segregation of the whole group of immigrant workers can be obtained by using the following expression:

$$
\text { Contribution of women }=\rho_{W}\left(\frac{C^{W}}{C^{I}}\right) \sqrt{\frac{\Phi_{2}\left(c^{W} ; t\right)}{\Phi_{2}\left(c^{I} ; t\right)}},
$$

where $C^{W}$ denotes the number of immigrant women and $C^{I}$ the number of immigrants. An analogous expression can be defined for the contribution of immigrant men. These contributions are, respectively, $53 \%$ and $47 \%$, while their demographic weights are $44 \%$ and 56\%. Therefore, gender segregation seems to play an important role in explaining the segregation of immigrants in Spain: the contribution of immigrant women to the segregation of immigrants is 9 percentage points higher than its employment weight. 


\subsection{Segregation of immigrants by group of age}

In order to explore segregation differences among immigrant workers related to their age, three groups are considered: young workers (16 to 30 years old), middle-aged workers (31 to 45 years old), and elderly workers (over 46 years old).
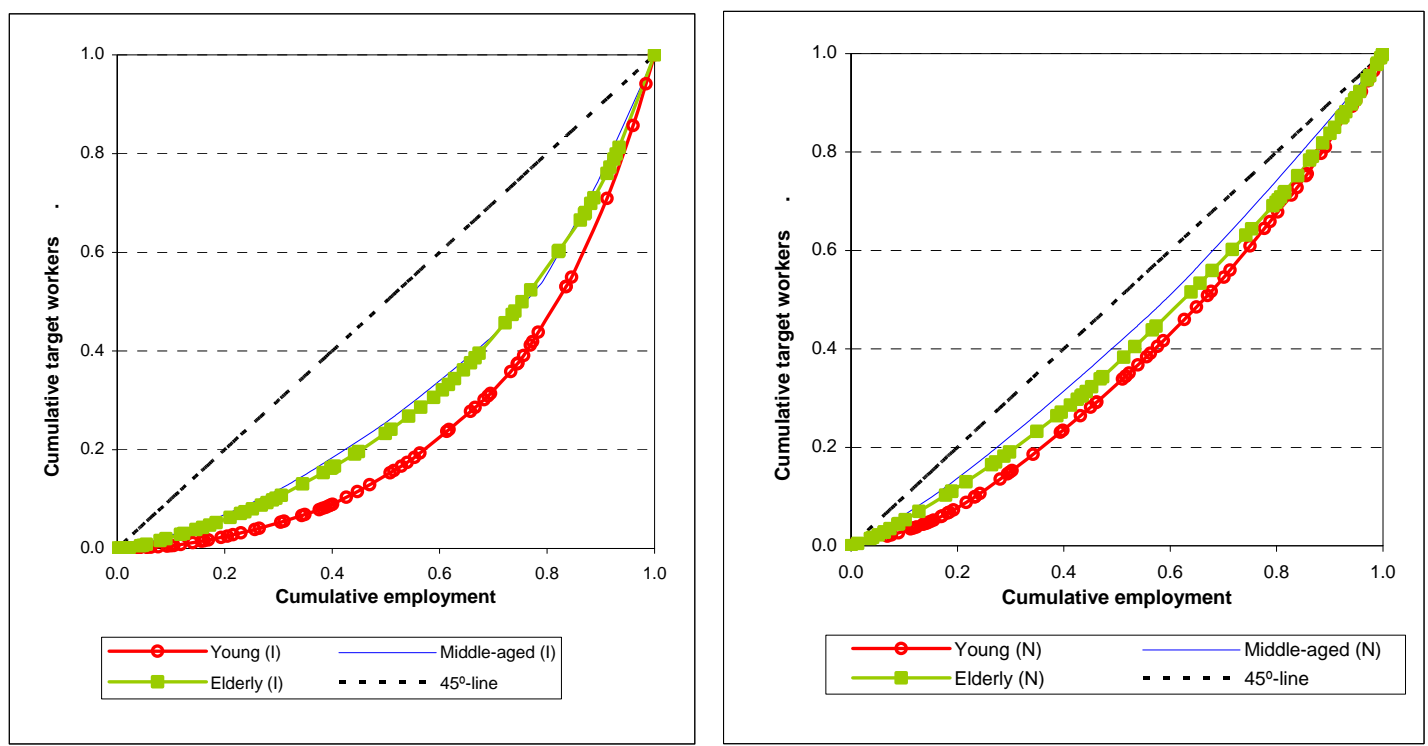

Figure 7. Segregation curves for immigrants and natives by age group (2007)

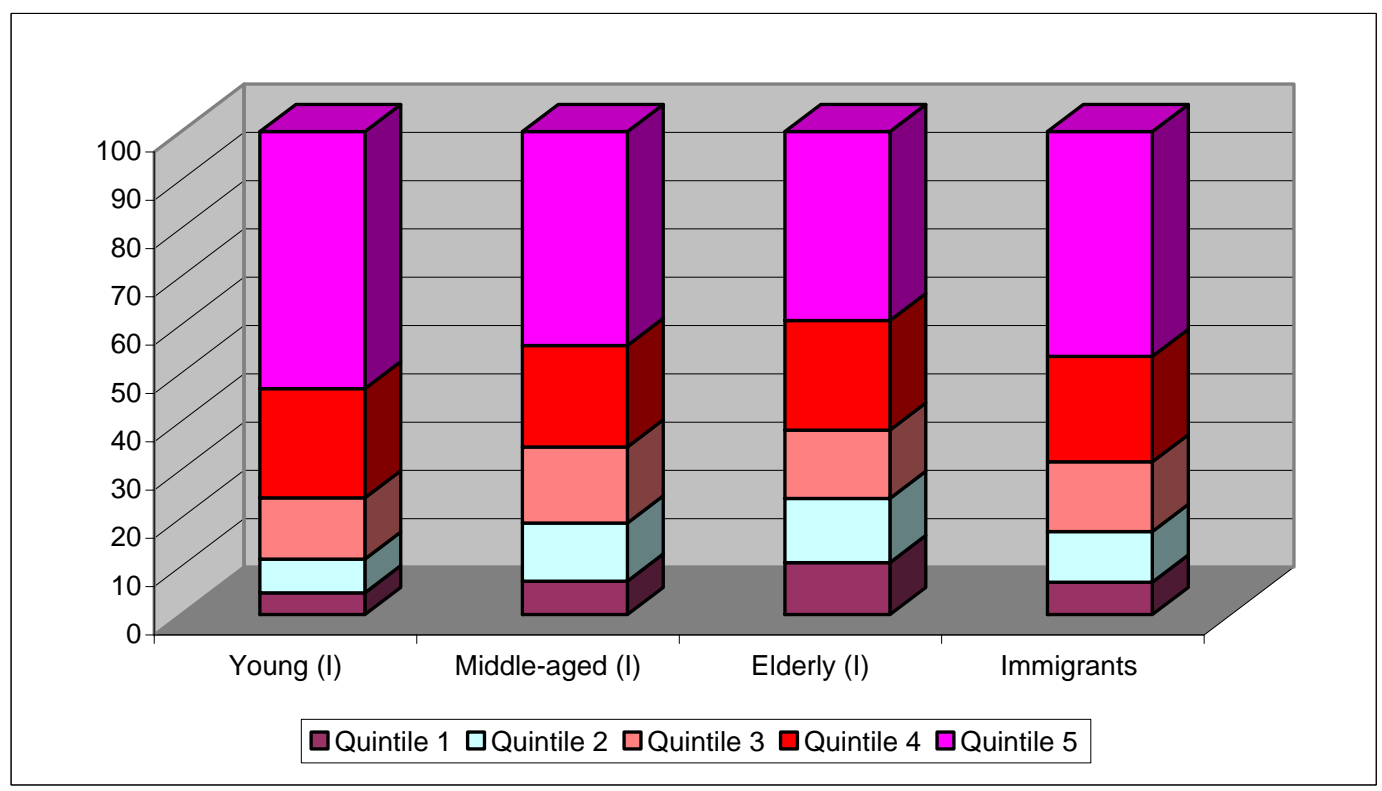

Figure 8. Distributions of immigrants across quintiles by age group (2007).

Figure 7 shows that young immigrants are more segregated than the remaining immigrants. In addition, the discrepancy between young and elderly workers is much more intense among immigrants than among natives. In fact, young native workers are 
distributed among quintiles of total employment (ranked from low to high native presence) in the same manner as middle-aged and elderly, while young immigrant workers tend to concentrate in occupations with high immigration shares to a greater extent than the remaining immigrants (over 53\% of young immigrants work in occupations included in the fifth quintile; see Figure 8, bar 1).

\subsection{Segregation of immigrants by years of residence}

We now classify immigrant workers by years of residence in Spain (without taking age into account). Four groups are considered: those who have been living in Spain for less than 3 years, those from 3 to less than 6 , those from 6 to less than 10, and those from 10 onwards. The segregation curves for these groups are shown in Figure 9.

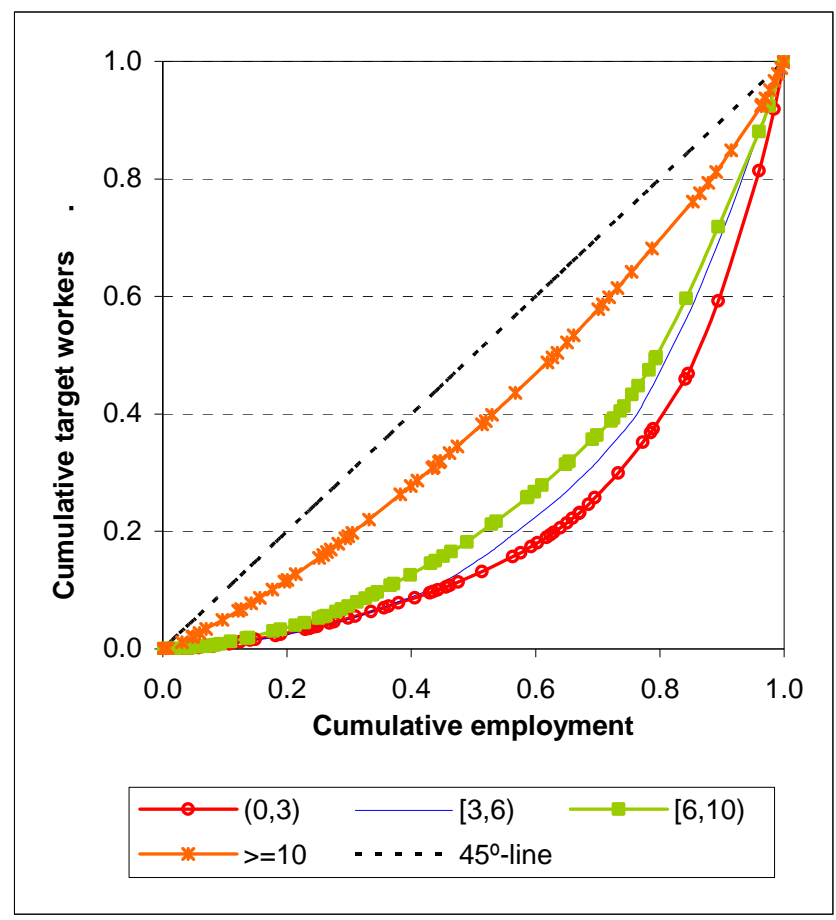

Figure 9. Local segregation curves for immigrants by years of residence in Spain (2007).

\begin{tabular}{|c|c|c|c|c|c|c|}
\hline LOCAL SEGREGATION & $\Phi_{0.1}^{g}$ & $\Phi_{0.5}^{g}$ & $\Phi_{1}^{g}$ & $\Phi_{2}^{g}$ & $D^{g}$ & $G^{g}$ \\
\hline Years of residence $<3$ & 0.89 & 0.57 & 0.54 & 0.69 & 0.44 & 0.56 \\
\hline $3 \leq$ Years of residence $<6$ & 0.69 & 0.46 & 0.41 & 0.44 & 0.38 & 0.50 \\
\hline $6 \leq$ Years of residence $<10$ & 0.44 & 0.35 & 0.32 & 0.34 & 0.34 & 0.44 \\
\hline Years of residence $\geq 10$ & 0.10 & 0.06 & 0.06 & 0.06 & 0.13 & 0.19 \\
\hline
\end{tabular}

Table 2. Local segregation indexes for immigrants by years of residence in Spain (2007). 
We can see that occupational segregation is clearly lower for those who have lived in Spain for 10 or more years. In fact, they are also more evenly distributed across quintiles of total employment (as shown in Figure 10). Even though the curves of the remaining groups cross, all of the indexes unambiguously point out that the higher the number of years of residence in Spain, the lower the segregation level (Table 2). ${ }^{15}$ In particular, we find that the highest segregation corresponds to newly arrived immigrants, who tend to concentrate in occupations with the highest share of immigrants in the economy (see Figure 10).

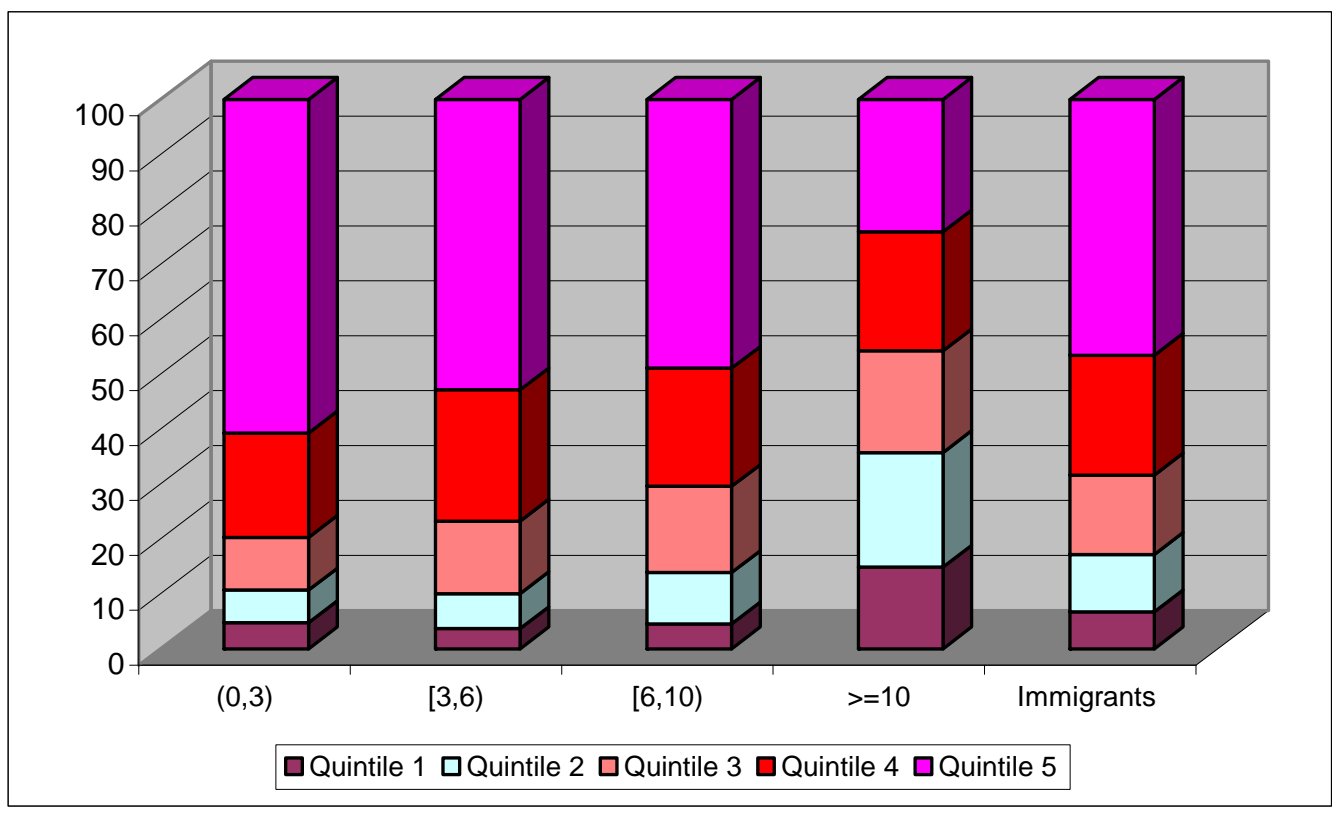

Figure 10. Distribution of immigrants across quintiles by years of residence (2007).

This result is in line with that obtained by Amuedo-Dorantes and De la Rica (2007) using another dataset (2001 Population Census) and methodology, which suggests that this finding is rather robust. Thus, following an econometric approach, these authors find that immigrants reach higher occupational achievements as their residency in Spain lengthens, even though there are important differences among regions of origin (the performance being especially positive for European countries outside the EU bloc and Latin America and negative for Africans, while immigrants from the EU bloc do not have occupational attainment discrepancies with respect to natives of the same skill level). Fernández and Ortega (2008) and Izquierdo et al. (2009) also provide evidence of assimilation of immigrants in Spain in terms of additional variables such as participation, unemployment

\footnotetext{
${ }^{15}$ Immigrant workers with 10 or more years of residence in Spain have the highest proportion of university degrees (33\%), while the figures for the other groups are close together (between 19\% and 21\%).
} 
rates, and wage gaps. In particular, they estimate a reduction of around half of the wage gap in the fifth or sixth year using the 2005 wave of the Continuous Sample of Working Histories (INE). ${ }^{16}$

\subsection{Segregation of immigrants by region of origin}

We next partition immigrant workers into six large regions of origin: the EU-25 and other countries, the Rest of Europe, Latin America, Africa, Asia, and the Rest of the World. ${ }^{17}$ Figure 11 illustrates that most immigrant workers come from Latin America while the EU25 bloc, Rest of Europe, and Africa have similar shares. Given the low presence of workers from the Rest of the World in the survey (0.5\% in 2007) one should be careful about drawing conclusions for this group.

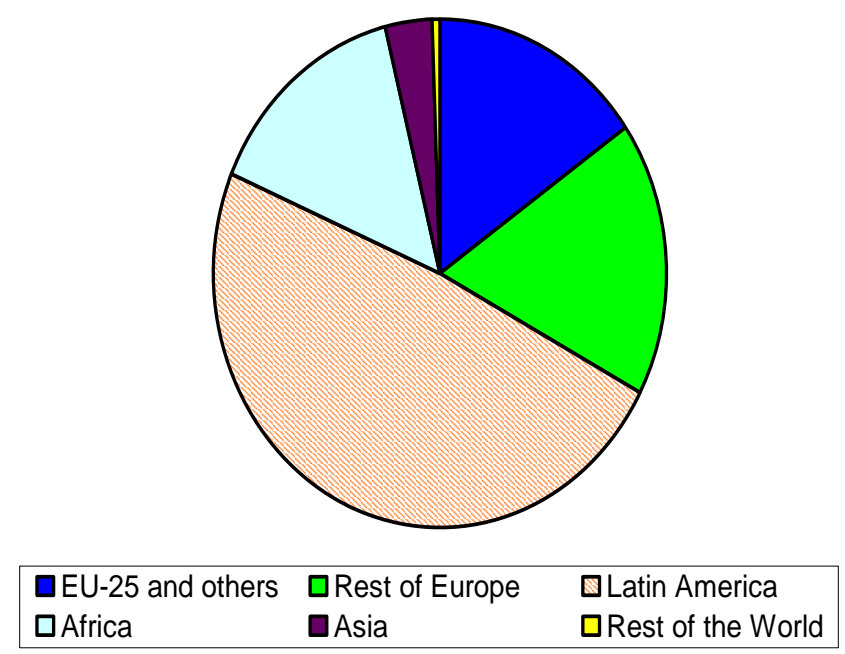

Figure 11. Distribution of immigrant workers by large regions of origin (2007).

Figure 12 shows the segregation curves of each of these six demographic groups. It is easy to see that immigrant workers from the EU-25 bloc have the lowest segregation (the corresponding curve is above those of the remaining regions), while Latin American

\footnotetext{
${ }^{16}$ The incidence of over-education and temporary contracts in the immigrant population remain, however, unaltered five years after arrival.

${ }^{17}$ We have included Iceland, Liechtenstein, Norway, and Switzerland in the group named "EU-25 bloc and others" since, even though these countries are not included in the EU, the immigration policies applied to them in Spain are similar to those within the bloc ("Régimen Comunitario de Residencia"). However, Romania and Bulgaria, which have been included in the EU-27 since 2007, were not included in this group since most of these immigrants are affected by a transitory regimen, which is similar to that of countries outside the European Union ("Régimen General de Extranjería"). The region named "Rest of the World" includes part of North America (Canada and the USA), Australasia, and Oceania.
} 
workers are less segregated than workers from Africa, Asia, and the Rest of Europe (see Table 3). In addition, according to most indexes, Asian workers are the most segregated group (excluding the Rest of the World), followed by immigrants from the Rest of Europe.

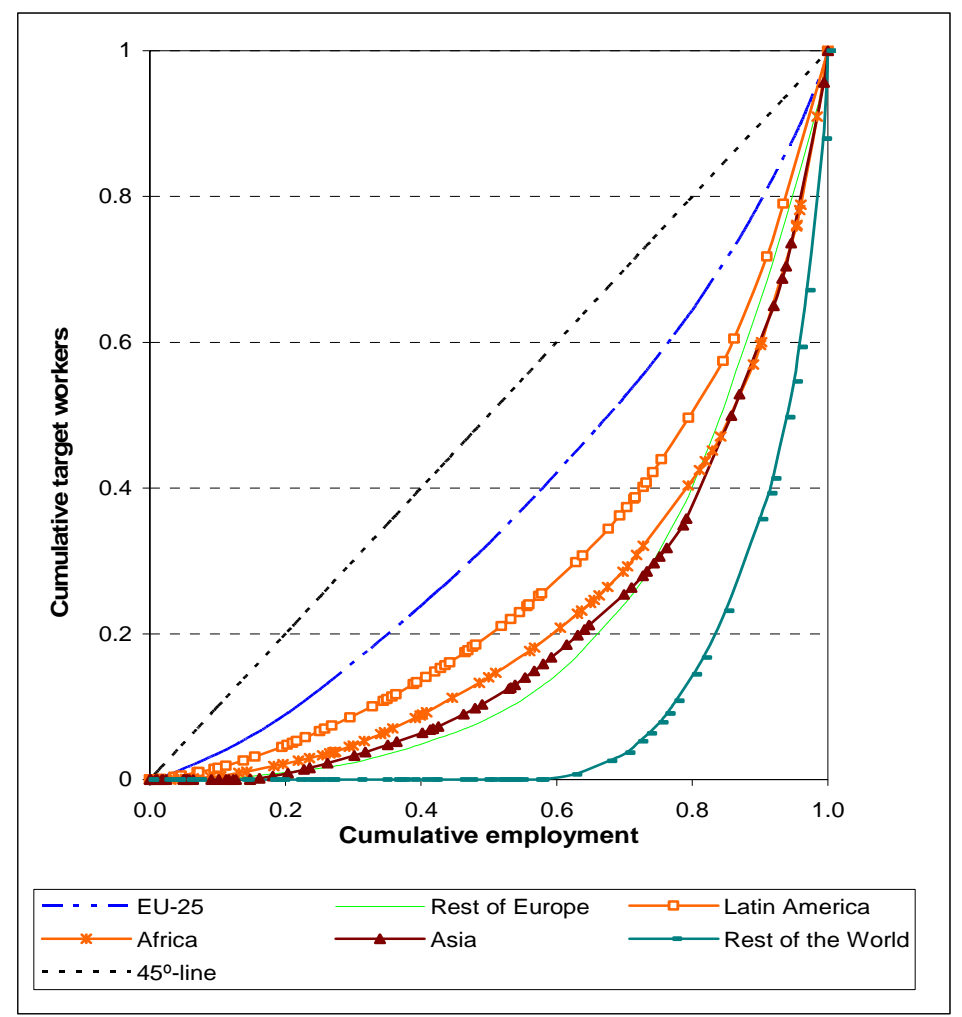

Figure 12. Local segregation curves for immigrants by large regions (2007).

\begin{tabular}{|c|c|c|c|c|c|c|}
\hline LOCAL SEGREGATION & $\Phi_{0.1}^{g}$ & $\Phi_{0.5}^{g}$ & $\Phi_{1}^{g}$ & $\Phi_{2}^{g}$ & $D^{g}$ & $G^{g}$ \\
\hline EU-25 and others & 0.15 & 0.12 & 0.11 & 0.12 & 0.18 & 0.26 \\
\hline Rest of Europe & 1.38 & 0.70 & 0.59 & 0.65 & 0.46 & 0.58 \\
\hline Latin America & 0.40 & 0.33 & 0.32 & 0.37 & 0.33 & 0.44 \\
\hline Africa & 0.84 & 0.55 & 0.53 & 0.72 & 0.41 & 0.55 \\
\hline Asia & 1.90 & 0.72 & 0.62 & 0.78 & 0.45 & 0.59 \\
\hline Rest of the World & 6.27 & 1.77 & 1.42 & 2.52 & 0.67 & 0.81 \\
\hline
\end{tabular}

Table 3. Local segregation indexes for immigrants by large regions (2007).

The study of the distribution of each large region across quintiles of total employment (ranked according to immigrant presence) shows that workers from the EU bloc are evenly distributed among them--i.e., they work in occupations with both high and low immigration shares (see Figure 13, bar 1). However, those from Latin America, Africa, 
and especially the Rest of Europe tend to concentrate in the fifth quintile--i.e., in occupations with the highest share of immigrants (see Figure 13, bars 2-4). ${ }^{18}$ All of the above suggests that the distribution of immigrant workers from the EU bloc across occupations clearly departs from that of other groups of immigrants (perhaps as consequence of the higher educational level of the former). ${ }^{19}$ The small group of immigrants from the Rest of the World also follows a pattern different from that of other immigrants since it tends to concentrate in professions associated with second and third university degrees in teaching.

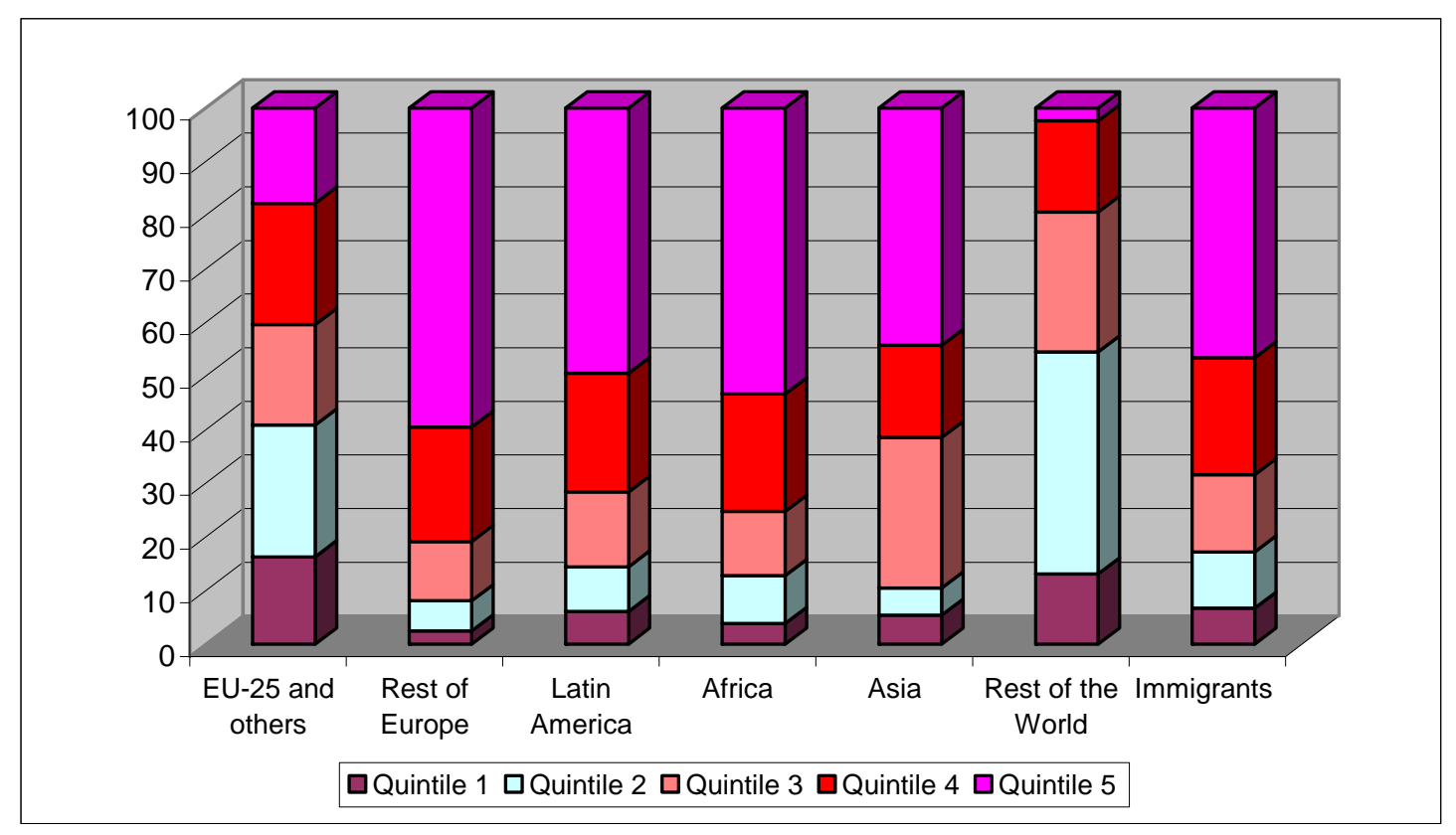

Figure 13. Distribution of immigrants across quintiles by region of origin (2007).

\section{Recent evolution of segregation: 1996-2009}

As mentioned above, immigration is a recent phenomenon in Spain. For this reason, even though the EPA gathers information from 1977 on, Figure 14 illustrates the evolution of occupational segregation of immigrants only from 1996 to 2009. The analysis reveals that the levels in 1996 were similar to those of 2001 according to most indexes, while Spain saw a noteworthy augment in the segregation level of its immigrant population between

\footnotetext{
${ }^{18}$ This concentration is even stronger in the case of female immigrants, as shown in Del Río and AlonsoVillar (2010b).

${ }^{19}$ Of the immigrant workers from the EU bloc, $43 \%$ have a university degree, compared to $25 \%$ from the Rest of Europe, 23\% from Asia, 20\% from Latin America, and 9\% from Africa.
} 
2001 and 2006. This increasing trend experienced a halt in the period 2006-2009, in which segregation seems even to decrease slightly.

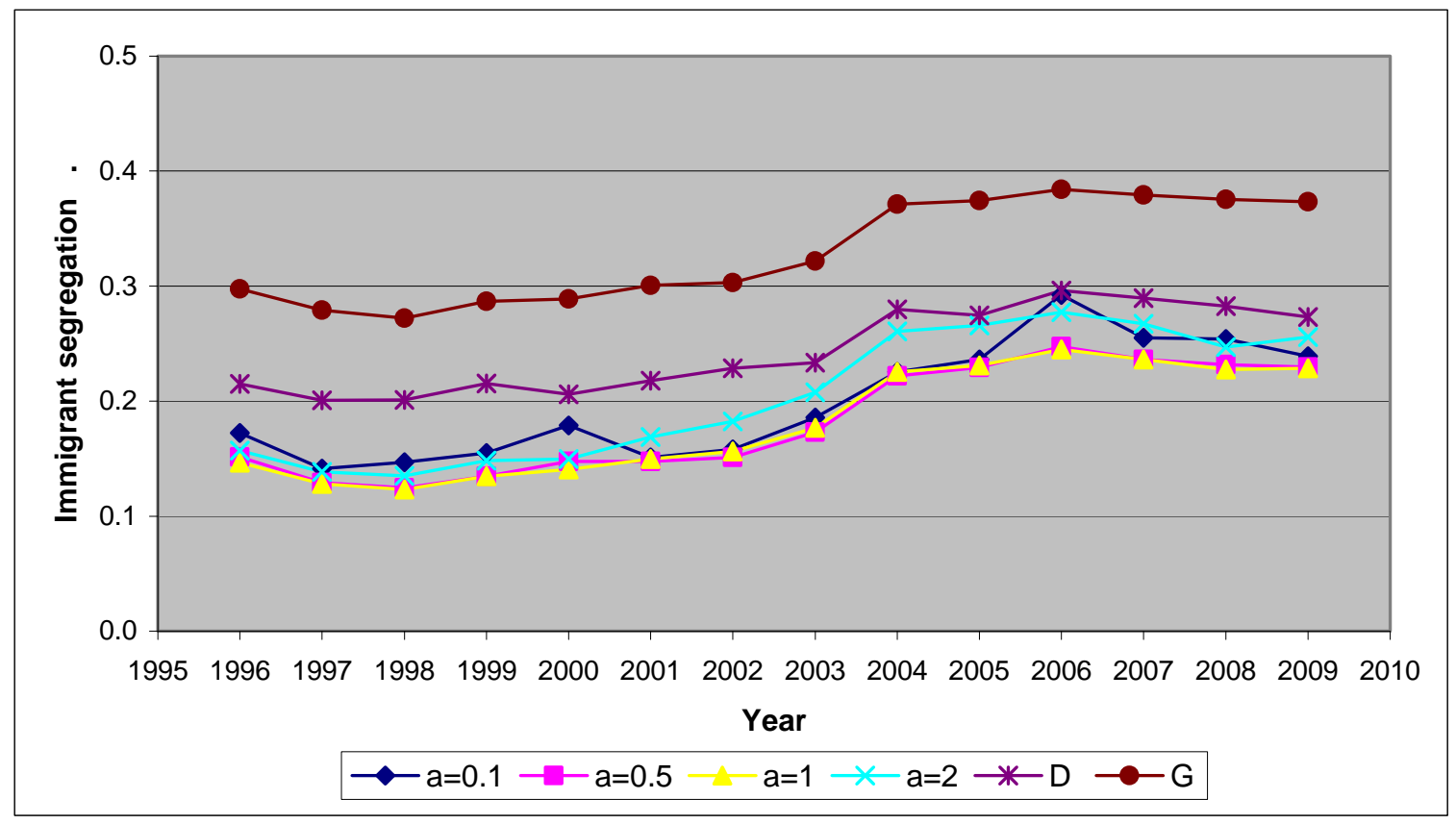

Figure 14. Evolution of the occupational segregation of immigrants (6 local indexes).

The first two periods of time, 1996-2001 and 2001-2006, share a remarkable reduction in the unemployment rates (as shown in Figure 4) and also a notable increase in the number of employed immigrants, which was extraordinarily high in the second period. Thus, according to the EPA, employed immigrants went from 618,080 in 2001 to almost 3 million in 2006. The growth of this group was much smaller, however, between 2006 and 2009 since in 2009 there were 3.2 million employed immigrants. The economic crisis, the effects of which started at the end of 2007, has had important consequences in the Spanish labor market, as reflected by the unemployment rate, which increased from $7.95 \%$ in the second quarter of 2007 to $18.83 \%$ in the fourth quarter of 2009. The employment implosion occurring during these last years has been accompanied by a small reduction in the occupational segregation of immigrant workers, as mentioned above. ${ }^{20}$ Our analysis suggests, therefore, a close relationship between the strong expansion of immigrant employment during the first years of this century and the increase in the occupational

\footnotetext{
${ }^{20}$ Between 2001 and 2006, nearly 4 million jobs were created, of which over 2 million were filled with immigrant workers. Even though between 2006 and 2009 there was a decline of 3.8\% in employment, immigrant employment still increased by $10.9 \%$ (note that the whole immigrant population also increased-see Figure 3).
} 
segregation level of this group, which halted with the recent sharp increase in unemployment.

We focus now on the 2001-2006 period since at that time there was a more intense change in the segregation level. We can decompose this change, $I\left(c_{2006} ; t_{2006}\right)-I\left(c_{2001} ; t_{2001}\right)$, in two components. The first component is related to changes in the occupational structure of the economy, $I\left(c_{2001} ; t_{2006}\right)-I\left(c_{2001} ; t_{2001}\right)$, and the second is related to changes in the distribution of immigrant workers across occupations, $I\left(c_{2006} ; t_{2006}\right)-I\left(c_{2001} ; t_{2006}\right)$. We find that the second effect was much higher than the first (and of opposite sign, see Table 4). ${ }^{21}$ The first effect is negative, which means that the shift in the occupational structure of the Spanish economy that took place at the beginning of this century made the employment distribution in 2006 become closer to the occupational distribution of immigrants in 2001. This shift was, however, accompanied by a stronger concentration of immigrants in occupations in which they already had an important presence. This explains the positive sign of the second component. In fact, when we focus on occupations in which immigrants tended to concentrate in 2001 (i.e., those in which the proportion of immigrants with respect to total immigrant workers was at least 2.5\%), we find that, on the one hand, these occupations experienced an increase of 4.5 percentage points in terms of total employment (see Table 5, column 2, and bottom row), rising from 40.3\% in 2001 to $44.8 \%$ in 2006. On the other hand, the immigrant employment rate in these occupations rose by 10.6 percentage points (see Table 5, column 3, and bottom row) since 54.6\% of immigrants concentrated in these occupations in 2001, while this percentage increased to $65.2 \%$ in 2006. All of the above implies that immigrants tended to concentrate in these occupations to a greater extent than natives did.

\begin{tabular}{|c|c|c|c|c|c|c|}
\hline $\begin{array}{c}\text { Decomposition of immigrant } \\
\text { segregation, 2001-2006 }\end{array}$ & $\Phi_{0.1}^{g}$ & $\Phi_{0.5}^{g}$ & $\Phi_{1}^{g}$ & $\Phi_{2}^{g}$ & $D^{g}$ & $G^{g}$ \\
\hline$I\left(c_{2001} ; t_{2006}\right)-I\left(c_{2001} ; t_{2001}\right)$ & -0.03 & -0.03 & -0.03 & -0.04 & -0.02 & -0.03 \\
\hline$I\left(c_{2006} ; t_{2006}\right)-I\left(c_{2001} ; t_{2006}\right)$ & 0.17 & 0.13 & 0.13 & 0.15 & 0.10 & 0.12 \\
\hline
\end{tabular}

Table 4. Decomposition of the segregation change between 2001 and 2006

\footnotetext{
${ }^{21}$ The same occurs when comparing 2006 and 2009, even though with reverse movements.
} 


\begin{tabular}{|c|c|c|c|c|c|c|}
\hline OCCUPATIONS & $\left(\frac{c_{j}^{g}}{C^{g}}\right)_{01}$ & $\left(\frac{t_{j}}{T}\right)_{06}-\left(\frac{t_{j}}{T}\right)_{01}$ & $\left(\frac{c_{j}^{g}}{C^{g}}\right)_{06}-\left(\frac{c_{j}^{g}}{C^{g}}\right)_{01}$ & $T_{06}-T_{01}$ & $C_{06}^{g}-C_{01}^{g}$ & $\frac{C_{06}^{g}-C_{01}^{g}}{T_{06}-T_{01}}$ \\
\hline $\begin{array}{l}\begin{array}{l}\text { Domestic employees and other indoor cleaning } \\
\text { personnel }\end{array} \\
\end{array}$ & 11.71 & 1.45 & 4.83 & 478,793 & 410,224 & 85.68 \\
\hline Catering service workers & 8.47 & 1.01 & 3.22 & 346,500 & 288,879 & 83.37 \\
\hline Workers at structural construction sites and the like & 4.99 & 0.30 & 3.51 & 234,442 & 217,081 & 92.59 \\
\hline Retail workers and the like & 4.32 & 0.10 & -0.12 & 213,574 & 95,859 & 44.88 \\
\hline Agricultural, livestock, and fishing laborers & 4.23 & -0.12 & 0.19 & 41,677 & 102,933 & 246.98 \\
\hline Construction laborers & 3.58 & 0.26 & 2.56 & 129,972 & 156,844 & 120.68 \\
\hline Personal service workers & 3.39 & 0.54 & 0.98 & 238,774 & 106,736 & 44.70 \\
\hline Administrative management support professionals & 3.14 & 0.17 & -1.72 & 173,869 & 22,135 & 12.73 \\
\hline $\begin{array}{l}\text { Workers dedicated to finishing construction and the } \\
\text { like (painters and related workers) }\end{array}$ & 2.80 & 0.12 & 0.73 & 162,366 & 85,684 & 52.77 \\
\hline $\begin{array}{l}\text { Financial and commercial transactions support } \\
\text { professionals }\end{array}$ & 2.68 & 0.43 & -0.85 & 191,042 & 36,804 & 19.27 \\
\hline $\begin{array}{l}\text { Professions associated with 2nd and 3rd cycle } \\
\text { university degrees in teaching }\end{array}$ & 2.61 & -0.01 & -1.16 & 88,445 & 26,281 & 29.72 \\
\hline $\begin{array}{l}\text { Management of companies with } 10 \text { or more } \\
\text { employees }\end{array}$ & 2.61 & 0.22 & -1.55 & 116,881 & 14,729 & 12.60 \\
\hline TOTAL & 54.56 & 4.47 & 10.61 & $2,416,335$ & $1,564,189$ & 64.73 \\
\hline
\end{tabular}

Table 5. Employment changes between 2001 and 2006 in the occupations in which immigrants tended to concentrate in 2001.

Table 5 also offers a summary of the changes that occurred in each of these occupations in terms of employment and immigrant presence. We see that domestic and other indoor cleaning work increased by nearly half a million jobs (see column 4), 85.7\% of which were filled with immigrants (column 6). The group of immigrants with the highest presence in this strongly feminized occupation (see Del Río and Alonso-Villar, 2010b) is Latin Americans, whose participation remained rather stable throughout the period (they comprise about $65 \%$ of the immigrants included in this occupation). On the contrary, the proportion of workers from the EU bloc working there decreased in the period (from 12\% to $4 \%$ ) in favor of European countries outside that bloc (which moved from $8 \%$ to $21 \%$ ). Other occupations that experienced remarkable increases in the period are catering and personal services-which are strongly feminized-and structural construction workhighly masculinized. The employment growth in these occupations was also largely filled with immigrants (accounting for between 93\% and 45\% of their growth). Moreover, occupations related to unskilled labor in agriculture/fishing and construction underwent a higher increase in the number of immigrants than in the number of total jobs, which suggests that natives are leaving these two occupations. On the contrary, a low proportion of the employment growth in administrative management support and management of 
companies with 10 or more employees was filled with immigrants, which decreased the concentration of immigrants in these occupations (see column 3).

\begin{tabular}{|l|c|c|c|c|c|c|}
\hline \multicolumn{1}{|c|}{ OCCUPATIONS } & $\left(\frac{c_{j}^{g}}{C^{g}}\right)_{06}$ & $\left(\frac{t_{j}}{T}\right)_{09}-\left(\frac{t_{j}}{T}\right)_{06}\left(\frac{c_{j}^{g}}{C^{g}}\right)_{09}-\left(\frac{c_{j}^{g}}{C^{g}}\right)_{06}$ & $T_{09}-T_{06}$ & $C_{09}^{g}-C_{06}^{g}$ & $\frac{C_{09}^{g}-C_{06}^{g}}{T_{09}-T_{06}}$ \\
\hline $\begin{array}{l}\text { Domestic employees and other indoor cleaning } \\
\text { personnel }\end{array}$ & 16.54 & 0.30 & 0.84 & 8,586 & 79,666 & 927.81 \\
\hline Catering service workers & 11.70 & 0.14 & -0.05 & $-10,214$ & 35,441 & -347.00 \\
\hline Workers at structural construction sites and the like & 8.50 & -1.04 & -1.57 & $-234,789$ & $-23,955$ & 10.20 \\
\hline Construction laborers & 6.13 & -1.09 & -2.79 & $-224,194$ & $-70,783$ & 31.57 \\
\hline Agricultural, livestock, and fishing laborers & 4.42 & -0.06 & -0.34 & $-22,553$ & 2,981 & -13.22 \\
\hline Personal service workers & 4.38 & 0.74 & 0.18 & 111,197 & 19,609 & 17.63 \\
\hline Retail workers and the like & 4.20 & 0.06 & 0.50 & $-26,944$ & 29,443 & -109.28 \\
\hline $\begin{array}{l}\text { Workers dedicated to finishing construction and the } \\
\text { like (painters and related workers) }\end{array}$ & 3.53 & -0.44 & 0.06 & $-112,500$ & 13,214 & -11.75 \\
\hline Drivers of vehicles for urban or road transport & 2.77 & 0.00 & 0.60 & $-28,275$ & 28,125 & -99.47 \\
\hline TOTAL & 62.17 & -1.39 & -2.58 & $-539,686$ & 113,744 & 406.51 \\
\hline
\end{tabular}

Table 6. Employment changes between 2006 and 2009 in the occupations in which immigrants tended to concentrate in 2006.

Between 2006 and 2009, the economic context changed dramatically and some of the occupations where immigrants tended to concentrate in 2006 experienced important employment destruction (see Table 6, column 4). ${ }^{22}$ This is the case of those occupations related to the construction sector: workers at structural construction sites, construction laborers, and workers dedicated to finishing construction jobs. However, it is also worth mentioning that despite the destruction of finishing construction jobs, the number of immigrants employed in this occupation increased (Table 6, column 5). Something similar occurred in the case of catering service workers, retail workers, and drivers. With respect to domestic and personal service staff, the figures show increases in both jobs and immigrant workers. Moreover, the number of immigrants in domestic services increased much more than the number of jobs. All of the above suggests that in occupations such as that of workers dedicated to finishing construction, catering service workers, retail workers, drivers, and domestic staff, jobs that were previously filled by nationals are now filled by immigrant workers.

It does not seem easy to reach a general conclusion about all these changes. However, the fact that occupations with a high immigrant presence have had so different performances,

\footnotetext{
${ }^{22}$ Table 6 shows those occupations in which the proportion of immigrants with respect to total immigrants in 2006 was above $2.5 \%$.
} 
together with the fact that the segregation level of immigrants according to most indexes had barely changed between 2006 and 2009 (Figure 14), suggests that the effects of these changes might have been balanced with each other (and, perhaps, they have been also offset by changes in occupations having a low immigrant presence). More research will be required in the next future to complete this picture since the employment destruction in Spain keeps going in 2010.

\section{Final comments}

Spain was, for a long time, an out-migration country. First, during the $19^{\text {th }}$ and the first half of the $20^{\text {th }}$ century, many Spanish workers emigrated to Latin American countries like Argentina, Venezuela, Uruguay, and Cuba, and later to other European countries (Germany, Switzerland, and France, especially). This pattern changed, however, at the end of the past century, when Spain became a receiving country, mainly from Latin America, but also from other European countries (including those of the EU). This paper has shown that the extraordinary increase Spain has experienced in its immigrant population in the last few years has been accompanied by an important rise in the occupational segregation of immigrant workers, even though the current economic crisis has apparently halted this trend. The intensification of segregation has been a consequence of two factors. On the one hand, those occupations in which immigrants tend to concentrate (in particular, domestic employees, catering workers, and workers at structural construction works) grew more than other occupations. On the other hand, jobs created from this employment growth were filled mostly by immigrants, all of which intensified the concentration of this group in a few occupations (mainly low paying).

Regarding the characteristics of employed immigrants, this paper has shown that the years of residency in Spain is a relevant variable in explaining the segregation of this group. In fact, occupational segregation of immigrants tends to decrease as their residency lengths, which may help to explain why young immigrants are much more segregated than the rest. This result is line with several studies that analyze the assimilation of immigrants in Spain using other approaches (Amuedo-Dorantes and De la Rica, 2007; Izquierdo et al., 2009). With respect to the effects of educational achievements on occupational segregation, the study has revealed that the distribution of highly-educated immigrants across occupations 
clearly departs from that of natives with the same educational level, since the latter are more segregated than other natives (perhaps as a consequence of the nature of the corresponding occupations), whereas the former are less segregated than other immigrants. This difference suggests that high-educated immigrants work both in occupations that match their skills and in others that do not, which is line with the higher extent of overeducation found in this group of citizens (Fernández and Ortega, 2008). In addition, it has been shown that gender is a relevant variable in analyzing the segregation of immigrant workers in Spain since women contribute to explain 53\% of the segregation of the whole group while they represent only $44 \%$ of the employed immigrants. Finally, the study has also given evidence of the remarkable differences in segregation regarding the country of immigrant origin. Thus, workers from the EU-25 bloc have the lowest segregation, perhaps as consequence of their higher educational level, while segregation is particularly intense among workers from Asia and European countries outside the bloc. 


\section{Acknowledgements}

The authors acknowledge financial support from the Instituto de Estudios Fiscales.

\section{References}

Albelda, R. (1986): Occupational segregation by race and gender, 1958-1981, Industrial and Labor Relations Review 39 (3), 404-411.

Alonso-Villar, O. and Del Río, C. (2010): Local versus overall segregation measures, Mathematical Social Sciences 60, 30-38.

Amuedo-Dorantes, C. and De la Rica, S. (2007): Labour market assimilation of recent immigrants in Spain, British Journal of Industrial Relations 45:2, 257-284.

Amuedo-Dorantes, C. and De la Rica, S. (2008): Complements or substitutes? Immigrant and native task specialization in Spain. CReAM Discussion Paper 16/08.

Bentolila, S., Dolado, J.J. and Jimeno, J.F. (2007): Does immigration affect the Phillips curve? Some evidence for Spain. Kiel Working Paper 1333.

Canal-Domínguez, J.F. and Rodríguez-Gutiérrez C. (2008): Analysis of wage differences between native and immigrant workers in Spain, Spanish Economic Review 10, 109-134.

Caparrós, A. and Navarro, M.L. (2008): Temporalidad y segregación ocupacional en España bajo la óptica de la nacionalidad. Mimeo, Universidad de Málaga.

Carrasco, R., Jimeno, J.J. and Ortega, A.C. (2004): The effect of immigration on the employment opportunities of native-born workers: Some evidence for Spain. Working Paper 04-61, Economics Series 22, Universidad Carlos III de Madrid.

Collado, M.D, Iturbe-Ormaetxe, I., and Valera, G. (2004): Quantifying the impact of immigration on the Spanish Welfare State, International Tax and Public Finance 11, 335353.

Del Río C. and Alonso-Villar, O. (2010a): Gender segregation in the Spanish labor market: An alternative approach, Social Indicators Research 98 (2), 337-362.

Del Río C. and Alonso-Villar, O. (2010b): Occupational segregation of immigrant women in Spain. ECINEQ WP2010-165, March.

Duncan, O.D. and Duncan, B. (1955): A methodological analysis of segregation indexes, American Sociological Review 20(2), 210-217. 
Fernández, C. and Ortega, C. (2008): Labour market assimilation of immigrants in Spain: Employment at the expense of bad job-matches, Spanish Economic Review 10: 83-107.

Frankel, D.M. and Volij, O. (2007): Measuring segregation. Working Paper 07009, Department of Economics, Iowa State University.

Hutchens, R.M. (2001): Numerical measures of segregation: desirable properties and their implications, Mathematical Social Sciences 42, 13-29.

Hutchens, R.M. (2004): One measure of segregation, International Economic Review 45(2), 555-578.

Instituto Nacional de Estadística (INE) (2009): Anuario Estadístico de España 1998-2009. http://www.ine.es/prodyser/pubweb/anuarios_mnu.htm.

Instituto Nacional de Estadística (INE) (2010a): Inebase: Principales Series de Población. http://www.ine.es/jaxi/menu.do?type=pcaxis\&path=/t20/e245/p08/\&file=pcaxis.

Instituto Nacional de Estadística (INE) (2010b): Inebase: Encuesta de Población Activa. http://www.ine.es/jaxi/menu.do?type=pcaxis\&path=\%2Ft22/e308_mnu\&file=inebase \&L=0

Izquierdo, M., Lacuesta, A. and Vegas, R. (2009): Assimilation of immigrants in Spain: A longitudinal analysis. Documentos de Trabajo 0904, Banco de España.

Karmel, T. and MacLachlan, M. (1988): Occupational sex segregation-Increasing or decreasing?, The Economic Record 64, 187-195.

King, M. (1992): Occupational Segregation by Race and Sex, 1940-88, Monthly Labor Review 115, 30-37.

Moir, H. and Selby Smith, J. (1979): Industrial segregation in the Australian labour market, Journal of Industrial Relations 21, 281-291.

Muñoz de Bustillo, R. and Antón, J.I. (2009): Immigration and social benefits in a Mediterranean welfare state: the case of Spain. Munich Personal RePEc Archive (MPRA) Paper 13849. http://mpra.ub.uni-muenchen.de/13849/

Parasnis, J. (2006): Segregation in the Australian Labour Market, Australian Economic Papers 45(4), 318-332.

Queneau, H. (2009): Trends in Occupational Segregation by Race and Ethnicity in the USA: Evidence from Detailed Data, Applied Economics Letters 16, 1347-1350.

Reardon, S.F. and Firebaugh, G. (2002): Measures of multigroup segregation, Sociological Methodology 32, 33-76.

Reher D.S. and Silvestre, J. (2009): Internal migration patterns of foreign-born immigrants in a country of recent mass immigration: Evidence from new micro data for Spain, International Migration Review 43(4), 815-849. 
Silber, J. (1989): On the measurement of employment segregation, Economics Letters 30, 237-243.

Silber, J. (1992): Occupational segregation indices in the multidimensional case: A note, The Economic Record 68, 276-277.

Simón, H., Sanromá, E. and Ramos, R. (2008): Labour segregation and immigration and native-born wage distributions in Spain: an analysis using matched employer- employee data, Spanish Economic Review 10, 135-168.

Springgs, W. E., and Williams, R.M. (1996): A Logit Decomposition Analysis of Occupational Segregation: Results for the 1970s and 1980s, Review of Economics and Statistics 78, 348-355.

United Nations, Department of Economic and Social Affairs, Population Division (2009): International Migration Report 2006: A Global Assessment, United Nations, New York. Available in: http://www.un.org/esa/population/unpop.htm.

Vázquez, P., Alloza, M., Vegas, R. and Bertozzi, S. (2008): Impact of the Rise in Immigrant Unemployment on Public Finances. Documento de Trabajo 2008-15, FEDEA. 


\section{Appendix}

\begin{tabular}{|c|c|c|}
\hline & $\begin{array}{c}\text { Immigrant workers } \\
\text { (\%) }\end{array}$ & $\begin{array}{c}\text { Native workers } \\
\text { (\%) }\end{array}$ \\
\hline GENDER & & \\
\hline Women & 43.6 & 40.5 \\
\hline Men & 56.4 & 59.5 \\
\hline EDUCATION & 40.9 & 44.2 \\
\hline Low education & 35.7 & 21.3 \\
\hline Intermediate education & 23.3 & 34.5 \\
\hline High education & & \\
\hline AGE & 34.6 & 25.6 \\
\hline Young (16-30 years old) & 49.1 & 42.0 \\
\hline Middle-age (31-45 years old) & 16.2 & 32.4 \\
\hline Elderly (46 years or more) & & \\
\hline YEARS OF RESIDENCE & 18.5 & - \\
\hline Years of residence $<3$ & 31.3 & - \\
\hline 3 $\leq$ Years of residence $<6$ & 26.8 & - \\
\hline $6 \leq$ Years of residence $<10$ & 23.4 & - \\
\hline Years of residence $\geq 10$ & & \\
\hline
\end{tabular}

Table 6. Summary of the main characteristics of immigrant and native workers (2007).

\begin{tabular}{|c|c|c|c|c|c|c|}
\hline LOCAL SEGREGATION & $\Phi_{0.1}^{g}$ & $\Phi_{0.5}^{g}$ & $\Phi_{1}^{g}$ & $\Phi_{2}^{g}$ & $D^{g}$ & $G^{g}$ \\
\hline Low education & 0.96 & 0.34 & 0.23 & 0.17 & 0.26 & 0.33 \\
\hline Intermediate education & 0.65 & 0.28 & 0.22 & 0.18 & 0.26 & 0.35 \\
\hline High education & 0.56 & 0.49 & 0.45 & 0.49 & 0.41 & 0.52 \\
\hline
\end{tabular}

Table 7. Local segregation indexes of natives by educational level (2007). 


\begin{tabular}{|c|c|c|c|}
\hline $\begin{array}{l}\text { The top } 10 \text { occupations with the highest presence of } \\
\text { immigrants }\end{array}$ & $c_{j}^{\mathrm{I}} / t_{j}$ & $t_{j} / T$ & $C_{j}^{I} / C^{I}$ \\
\hline 96. Construction laborers & 45.28 & 2.41 & 6.69 \\
\hline 94. Agricultural and livestock and fishing laborers & 43.83 & 1.60 & $4 . .31$ \\
\hline $\begin{array}{l}\text { 91. Domestic employees and other indoor cleaning } \\
\text { personnel }\end{array}$ & 40.43 & 6.59 & 16.37 \\
\hline 50. Catering services workers & 36.02 & 4.84 & 10.70 \\
\hline 71. Workers at structural construction works and the like & 30.14 & 5.13 & 9.51 \\
\hline 74. Extractive industry workers & 27.91 & 0.14 & 0.25 \\
\hline 90. Unskilled retail workers & 25.10 & 0.44 & 0.67 \\
\hline 97. Manufacturing industry laborers & 22.83 & 1.05 & 1.47 \\
\hline 98. Transport labourers and freight handlers & 20.88 & 1.24 & 1.59 \\
\hline 78. Food, beverage and tobacco industry workers & 20.74 & 1.00 & 1.28 \\
\hline Total: & & 24.44 & 52.84 \\
\hline $\begin{array}{l}\text { The bottom } 10 \text { occupations with the lowest presence } \\
\text { of immigrants }\end{array}$ & $c_{j}^{\mathrm{I}} / t_{j}$ & $t_{j} / T$ & $c_{j}^{I} / C^{I}$ \\
\hline $\begin{array}{l}\text { 10. Executive and legislative power of the public } \\
\text { administration; management of organizations of interest }\end{array}$ & 0.00 & 0.13 & 0.00 \\
\hline 95. Mining labourers & 0.00 & 0.02 & 0.00 \\
\hline 82. Fixed machinery operator foreman & 0.28 & 0.23 & 0.00 \\
\hline $\begin{array}{l}\text { 80. Team managers and those in charge in fixed industrial } \\
\text { installations }\end{array}$ & 1.00 & 0.14 & 0.01 \\
\hline 62. Skilled workers employed in other agricultural activities & 2.66 & 0.31 & 0.05 \\
\hline $\begin{array}{l}\text { 27. Professions associated with a 1st cycle university degree } \\
\text { in natural and health sciences, except in optics, physiotherapy } \\
\text { and related sciences }\end{array}$ & 2.78 & 1.08 & 0.18 \\
\hline $\begin{array}{l}\text { 28. Professions associated with a 1st cycle university } \\
\text { degree in teaching }\end{array}$ & 3.90 & 1.92 & 0.46 \\
\hline 23. Law professionals & 4.51 & 0.75 & 0.21 \\
\hline $\begin{array}{l}\text { 40. Accounting, finance services employees, and production } \\
\text { and transport support services employees }\end{array}$ & 5.35 & 1.66 & 0.54 \\
\hline $\begin{array}{l}\text { 32. Technicians in child education, flight instructors, vehicle } \\
\text { navigation and driving }\end{array}$ & 5.45 & 0.22 & 0.07 \\
\hline Total: & & 6.46 & 1.52 \\
\hline
\end{tabular}

Table 8. The top (bottom) 10 occupations with the highest (lowest) immigrant presence in 2007. Note: All figures are presented in percentage.

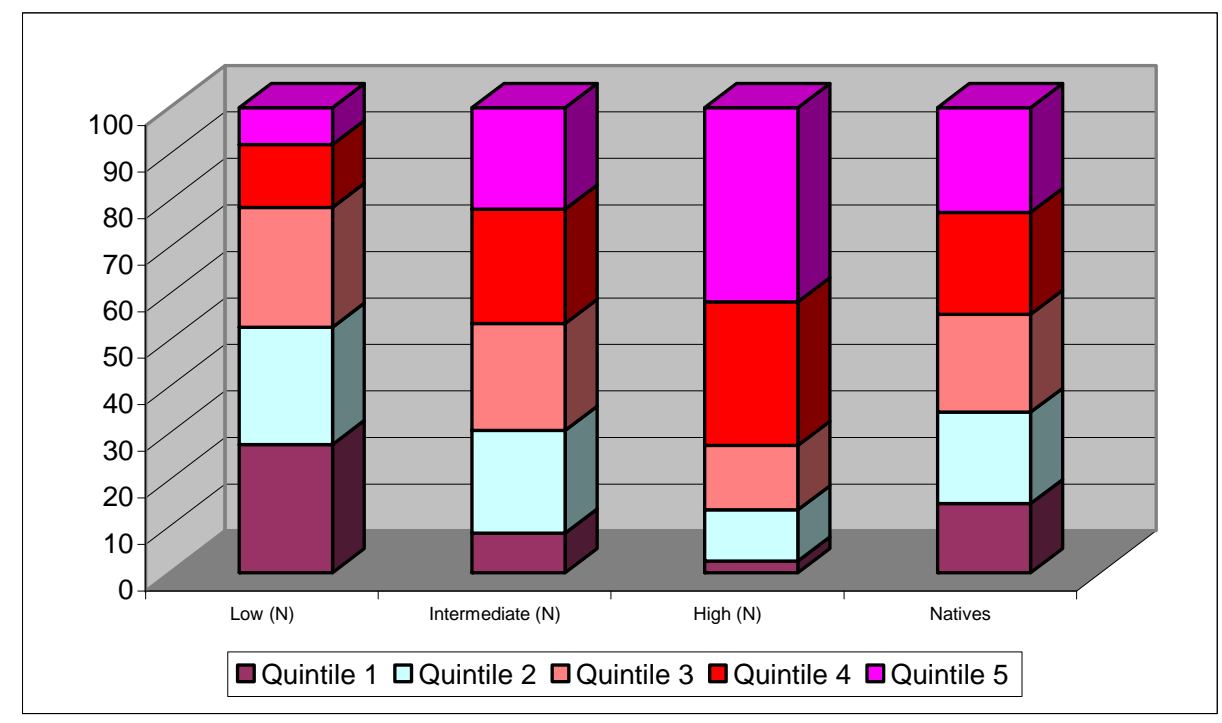

Figure 15. Distributions of native workers across quintiles by educational level (2007). 